\title{
Analysis of flow and phase interaction characteristics in a gas-liquid two-phase pump
}

\author{
Wenwu Zhang, Zhiyi Yu*, and Yongjiang Li \\ School of Mechanical Engineering, Beijing Institute of Technology, Beijing 100081, PR China
}

Received: 16 May 2018 / Accepted: 24 September 2018

\begin{abstract}
To analyze the characteristics of internal flow and phase interaction in a gas-liquid two-phase pump, the influence of Inlet Gas Void Fraction $(I G V F)$, discharge coefficient, and medium viscosity were investigated using medium combinations of air-water and air-crude. Simulations were performed using ANSYS_CFX at different $I G V F$ s and various values of discharge coefficient. Structured grid for the full flow passage was generated using ICEM_CFD and TurboGrid. Under conditions of $I G V F=0 \%$ (pure water) and $I G V F=15 \%$, the reliability of numerical method was proved by means of the comparison with the experimental data of external characteristic. The results for air-water combination showed a uniform gas distribution in the inlet pipe, and formation of a stratified structure in the outlet pipe. The gas in impeller gathered at the hub because of the rotation of the impeller, also, the interphase forces increased with the increased $I G V F$. For the two medium combinations, the drag force was the largest interphase force, followed by added mass and lift forces, and then the turbulent dispersion force was the least, which can be neglected. Because of the larger viscosity of crude than that of water, the variation trend of interphase forces in the impeller is relatively smooth along the flow direction when the medium combination was air-crude.
\end{abstract}

\section{Introduction}

With the technological development and the demand for gas-liquid two-phase transport in industry, the gas-liquid multiphase pump is widely used in petroleum, chemical engineering, nuclear industries, etc. [1-4]. The gas-liquid multiphase pump usually accompanied more complex internal flow phenomena than the single-phase pump because of its two-phase transport process including the polymerization and the division of bubbles, and the intermixing and the separation among mediums.

Thus far, except for the optimization design, many studies on multiphase pumps with the centrifugal or axial impeller were forced on the transport properties. For the multiphase pump with a centrifugal impeller, Minemura and Murakami [5-7] investigated the motion of air bubble in a centrifugal pump, and obtained the controlling factors for the bubble motion including the pressure gradient, the drag force, and the inertia force. Caridad et al. [8] simulated a centrifugal pump with two-phase flow conditions and concluded that the detriment in head increased with the increase in bubble diameter. For the multiphase pump with an axial impeller, Zhang and Tan [9] analyzed the energy performance and the pressure fluctuation in a multiphase pump. They found the gas distribution in the pump was

\footnotetext{
* Corresponding author: yuzhiyi@bit.edu.cn
}

uneven because of the existence of density difference between the gas and liquid phases. Tremante et al. [10] carried out the simulation on a gas-liquid two-phase axial flow pump, and observed that the gas pockets appeared at the blade suction surface.

Interphase behavior is difficult to understand in twophase flow field. Different studies on the gas-liquid phase interaction have been conducted for same and different flow patterns at different IGVFs [11-13]. These studies were conducted using the horizontal or inclined pipes only in the non-rotating machinery. Whereas the flow is more disordered in multiphase pumps than that in static pipes because of the rotor-stator interaction. Although $\mathrm{Yu}$ et al. [14] analyzed the variation trend of the interphase forces in a single impeller passage, the understanding of the gasliquid interphase behavior in multiphase rotodynamic pumps is still insufficient. Meanwhile, considering the complexity, safety and reusability of the testing system of multiphase pumps, the air-water combination has been usually used as the working medium [15]. Thus, few studies have been performed on the characteristics of phase interaction as well as the difference of transport properties caused by the change of medium viscosity in multiphase pumps.

On the basis of the above introduction, the three-dimensional (3D) simulation of the gas-liquid flow in a multiphase pump for a full passage was carried out in this study. Furthermore, the medium combinations of air-water, and 
air-crude were used to explore the distribution of Gas Void Fraction (GVF) as well as the interphase behavior of the gas-liquid two-phase flow in the impeller, and the inlet and outlet pipes. The purpose of this study is to have further understanding of the effects of different inlet parameters (inlet gas void fraction, discharge, medium viscosity) on the characteristics of flow and phase interaction in such pumps.

\section{Computational model and structured grid}

The study was conducted on a helico-axial flow pump dealing with a gas-liquid two-phase flow. Its main design specifications are described below: the diameter of impeller $(D)$ was $210 \mathrm{~mm}$, the numbers of impeller blades $(Z)$ were 4 , the discharge $\left(Q_{\mathrm{d}}\right)$ was $35.45 \mathrm{~m}^{3} / \mathrm{h}$, the rotating speed $(n)$ was $1500 \mathrm{r} / \mathrm{min}$, and the head $(H)$ was $15 \mathrm{~m}$. Figure 1 shows the calculation model of the multiphase pump with its inlet and outlet pipes, and impeller.

The grids of the inlet and outlet pipes and the impeller were generated with ICEM_CFD and TurboGrid, respectively, as shown in Figure 2. Furthermore, H/J/C/O topologies were adopted for the impeller to ensure its grid quality. In addition, the analysis for grid independence was conducted at three discharge conditions $(\varphi=0.034$, $0.043,0.051)$ to reduce the computational memory and time, as listed in Table 1. Here, by adjusting the size of elements next to the wall, the $y+$ values of the impeller extracted through CFD Post for these four grid densities were kept around 20. It shows that these four grid densities have no great effect on the pump head. Therefore, Grid _I was finally adopted in the present study.

\section{Numerical methodology}

\subsection{Governing equations}

Two-fluid model was adopted in this study to predict the internal flow of the multiphase pump. In this model, each fluid has its own conservation equations and various interactions between the two fluids are considered. Therefore, two-fluid model has been widely used in recent years because of its high computational accuracy [16-18]. Meanwhile, in this study, ANSYS_CFX 15.0 was implemented to solve the steady Reynolds-Averaged Navier-Stokes (RANS) equations. The governing equations for incompressible fluid are written below [19-22].

Continuity equation:

$$
\nabla \cdot\left(\alpha_{\mathrm{k}} \rho_{\mathrm{k}} \boldsymbol{w}_{\mathrm{k}}\right)=0 .
$$

Momentum equation:

$$
\nabla \cdot\left(\alpha_{\mathrm{k}} \rho_{\mathrm{k}} \boldsymbol{w}_{\mathrm{k}} \boldsymbol{w}_{\mathrm{k}}-\alpha_{\mathrm{k}} \tau\right)=-\alpha_{\mathrm{k}} \nabla p+\boldsymbol{M}_{\mathrm{k}}+\alpha_{\mathrm{k}} \rho_{\mathrm{k}} \boldsymbol{f}_{\mathrm{k}},
$$

where $\tau$ denotes the viscous stress tensor; $\alpha_{\mathrm{k}}, \boldsymbol{M}_{\mathrm{k}}, f_{\mathrm{k}}$, and $w_{\mathrm{k}}$ stand for the void fraction, the interphase force, the mass force, and the velocity of $\mathrm{k}$ phase, respectively.

Meanwhile, SST $k-\omega$ turbulence model was applied for solving the turbulent viscosity. In this model, the $k-\varepsilon$ and

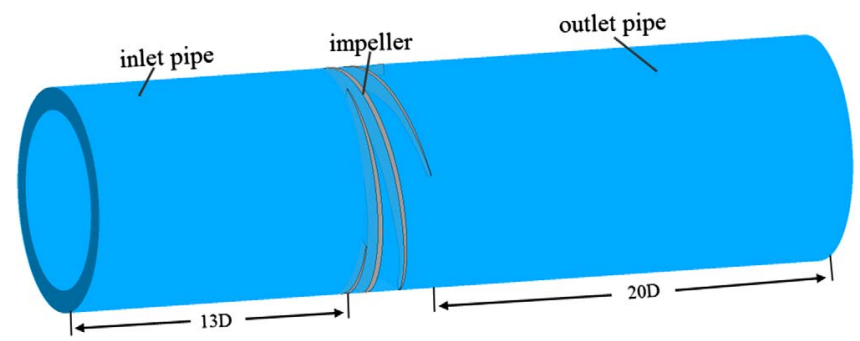

Fig. 1. 3D calculation model of the multiphase pump.

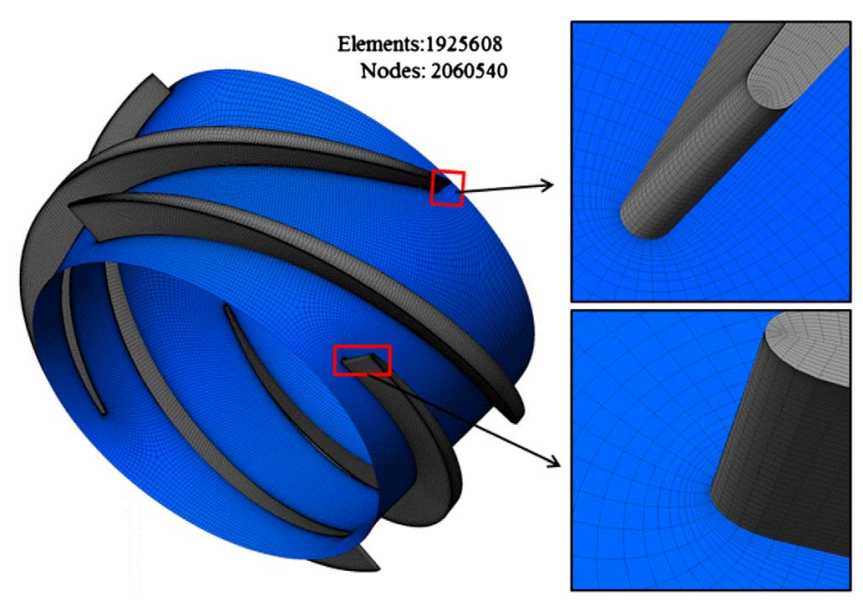

Fig. 2. Structured grid for impeller passage.

$k$ - $\omega$ models are implemented for the boundary layer and the main flow regions, respectively, thus it can predict accurately for the flow separation in the pump [23]:

$$
\mu_{\mathrm{t}}=\frac{\rho_{\text {mix }} a_{1} k}{\max \left(a_{1} \omega, S F_{2}\right)},
$$

here, $a_{1}$ is the model constant $\left(a_{1}=5 / 9\right) ; S, \rho_{\text {mix }}, F_{2}$ represent the invariant measure of strain rate, the mixture density, and the blending function, respectively.

\subsection{Interphase force}

In addition to the centrifugal force, inertia force, gravity and the pressure difference, the two phases in the multiphase pump are also experienced the interphase forces. The interphase forces were extracted using the CFX Expression Language (CEL) and analyzed in this study. Furthermore, the interphase forces in the gas-liquid twophase flow mainly include the drag, added mass force, lift, turbulent dispersion force as well as Basset effect and Magnus effect [24], while the latter two can be neglected for the internal flow in multiphase pumps [25, 26]. Thus, the total gas-liquid interphase force in this study was expressed as follows:

$$
\boldsymbol{M}_{\mathrm{k}}=\boldsymbol{D}_{\mathrm{k}}+\boldsymbol{L}_{\mathrm{k}}+\boldsymbol{T}_{\mathrm{k}}+\boldsymbol{A}_{\mathrm{k}},
$$


Table 1. Analysis for grid independence.

\begin{tabular}{llllllll}
\hline & & & & & & \multicolumn{2}{c}{$\mathrm{H} / \mathrm{H}_{\mathrm{I}}$} \\
\cline { 6 - 8 } Items & Inlet pipe & Outlet pipe & Impeller & Whole passage & $\varphi=0.034$ & $\varphi=0.043$ & $\varphi=0.051$ \\
\hline Grid_I & 518364 & 373932 & 1925608 & 2817904 & 1 & 1 & 1 \\
Grid_II & 518364 & 373932 & 2332168 & 3224464 & 0.9980 & 0.9994 & 0.9962 \\
Grid_III & 602482 & 463932 & 2903646 & 3970060 & 0.9980 & 0.9988 & 0.9949 \\
Grid_IV & 698362 & 524812 & 3241862 & 4465036 & 0.9975 & 0.9971 & 0.9947 \\
\hline
\end{tabular}

Note. $\mathrm{H}_{\mathrm{I}}$ is the head at Grid_I condition.

where $D_{\mathrm{k}}, L_{\mathrm{k}}, T_{\mathrm{k}}$ and $A_{\mathrm{k}}$ denote the interphase forces of drag, lift, turbulent dispersion and added mass, respectively.

The drag models involved in the gas-liquid two-phase flow mainly include Ishii Zuber, Grace, and Schiller Naumann models. The former two are closely related to the particle shapes, and they are rarely used in the simulation of the multiphase pump. Therefore, the widely applied Schiller Naumann model was considered in this study $[27,28]$. The drag force per unit volume can be described as follows:

$$
\boldsymbol{D}_{1}=-\boldsymbol{D}_{\mathrm{g}}=\frac{3}{4} \boldsymbol{C}_{D} \frac{\rho_{\mathrm{l}}}{D_{b}} \alpha_{\mathrm{g}}\left|\boldsymbol{w}_{\mathrm{g}}-\boldsymbol{w}_{1}\right|\left(\boldsymbol{w}_{\mathrm{g}}-\boldsymbol{w}_{\mathrm{l}}\right)
$$

here, $\boldsymbol{w}_{\mathrm{g}}$ and $\boldsymbol{w}_{1}$ represent the velocity of gas and liquid, respectively; $D_{b}$ is the diameter of gas bubble and is given $0.4 \mathrm{~mm}$ according to the experimental value; and $C_{D}$ is the drag coefficient. According to the references [14, 29], the drag coefficient was modified through the CFX expression language (CEL) and expressed as:

$C_{\mathrm{D}}=\max \left(\frac{24}{\operatorname{Re}_{\mathrm{b}}}\left(1+0.1 \mathrm{Re}_{\mathrm{b}}^{0.75}\right), \frac{2}{3} D_{\mathrm{b}} \sqrt{\frac{\left(\rho_{1}-\rho_{\mathrm{g}}\right)}{\sigma}}\left(1-\alpha_{\mathrm{g}}\right)^{-0.5}\right)$

where $\sigma$ is the surface tension coefficient; $\rho_{\mathrm{l}}$ and $\rho_{\mathrm{g}}$ are the density of liquid and gas; $\alpha_{\mathrm{g}}$ is the gas void fraction; $\operatorname{Re}_{b}$ is the bubble Reynolds number and given as follows:

$$
\operatorname{Re}_{b}=\frac{\rho_{\mathrm{l}} D_{\mathrm{b}}\left|\boldsymbol{w}_{1}-\boldsymbol{w}_{\mathrm{g}}\right|}{\mu_{1}}\left(1-\alpha_{\mathrm{g}}\right)
$$

where $\mu_{1}$ is the liquid molecular viscosity. The lift, turbulent dispersion and added mass forces can be described by the following expressions (8)-(10), respectively:

$$
\begin{gathered}
\boldsymbol{L}_{\mathrm{l}}=-\boldsymbol{L}_{\mathrm{g}}=C_{\mathrm{L}} \alpha_{\mathrm{g}} \rho_{\mathrm{l}}\left(\boldsymbol{w}_{\mathrm{g}}-\boldsymbol{w}_{\mathrm{l}}\right) \times\left(\nabla \times \boldsymbol{w}_{\mathrm{l}}\right) \\
\boldsymbol{T}_{\mathrm{l}}=-\boldsymbol{T}_{\mathrm{g}}=-C_{T} \rho_{\mathrm{l}} k \nabla \alpha_{\mathrm{l}} \\
\boldsymbol{A}_{\mathrm{l}}=-\boldsymbol{A}_{\mathrm{g}}=-\boldsymbol{\rho}_{\mathrm{l}} \boldsymbol{C}_{\boldsymbol{A}} \boldsymbol{\alpha}_{\mathrm{g}}\left(\frac{\mathbf{D} \boldsymbol{w}_{\mathrm{g}}}{\mathrm{D} t}-\frac{\boldsymbol{D} \boldsymbol{w}_{\mathrm{l}}}{\mathrm{D} t}\right)
\end{gathered}
$$

where $k$ is the turbulence kinetic energy of liquid. According to the relevant research by far, the coefficients of lift, turbulent dispersion and added mass forces were usually kept constant, i.e., $\mathrm{C}_{L}=0.5$ [30], $\mathrm{C}_{T}=0.1$ [14], and $\mathrm{C}_{A}=0.5[31]$.

\subsection{Settings of simulation and medium properties}

The settings of simulation and the properties of air-water and air-crude medium combinations are presented in Tables 2 and 3, respectively. Especially, it can be obtained from Table 3 that the smaller density difference exists between water and crude, while the viscosity of crude is about thirty-one times as large as that of water.

\section{Results and discussions}

\subsection{Test system and validation of simulation results}

A schematic diagram of the testing system is presented in Figure 3. Here, considering the complexity, safety and reusability of the testing system, a combination of air-water was chosen as the transporting medium. In this testing system, the air was provided by a compressor and evenly mixed with the water in a mixer before entry into the multiphase pump, that is, the flow pattern is bubbly flow in the inlet pipe. The water pipeline was the closed cycle, while the air pipeline was open system, and after one cycle, the gas will spill out from the water tank. Experimental measurements at different discharges and $I G V F_{\mathrm{S}}$ were made in two steps, the first was to fix the liquid discharge, and the second was the control of total mass discharge by adjusting the gas valve. Meanwhile, the float and turbine flowmeters, with an accuracy of $\pm 0.5 \%$, were installed to obtain the air and water discharges, respectively. A torque sensor with an accuracy of $\pm 0.1 \%$ was used to monitor the rotating speed and torque of the pump, and the pressure gauges with an accuracy of $\pm 0.25 \%$ were installed at the inlet and outlet of the pump so as to obtain the tested head.

Figure 4 presents the numerical and experimental results under conditions of $I G V F=0 \%$ (pure water) and $I G V F=15 \%$ when the rotating speed of the pump is $1500 \mathrm{r} / \mathrm{min}$. Here, the calculations of $I G V F$, discharge coefficient $\varphi$ (horizontal axial), and head coefficient $\psi$ (vertical axial) are described by the following expressions, respectively:

$$
I G V F=Q_{\mathrm{g}} /\left(Q_{\mathrm{g}}+Q_{\mathrm{l}}\right)
$$


Table 2. Settings of boundaries and solutions.

\begin{tabular}{lll}
\hline Types & \multicolumn{1}{c}{ Items } & \multicolumn{1}{c}{ Settings } \\
\hline Boundaries & Inlet & Total mass discharge and corresponding $I G V F$ \\
& Outlet & Average static pressure \\
& Wall & No-slip \\
Rotor-stator interfaces & Frozen-stator \\
Solutions & Advection term & Second order upwind scheme \\
& Turbulence term & Second order upwind scheme \\
& RMS residual & $1 \times 10^{-4}$ \\
\hline
\end{tabular}

Table 3. Medium properties in the simulation.

\begin{tabular}{llll}
\hline Items & \multicolumn{1}{c}{ Air } & Water & Crude \\
\hline Molar mass $\left(\mathrm{kg} \mathrm{kmol}^{-1}\right)$ & 29.0 & 18.0 & 300 \\
Density $\left(\mathrm{kg} \mathrm{m}^{-3}\right)$ & 1.2 & 997 & 863 \\
Dynamic viscosity $\left(\mathrm{kg} \mathrm{m}^{-1} \mathrm{~s}^{-1}\right)$ & $1.8 \times 10^{-5}$ & $8.9 \times 10^{-4}$ & $273.6 \times 10^{-4}$ \\
\hline
\end{tabular}

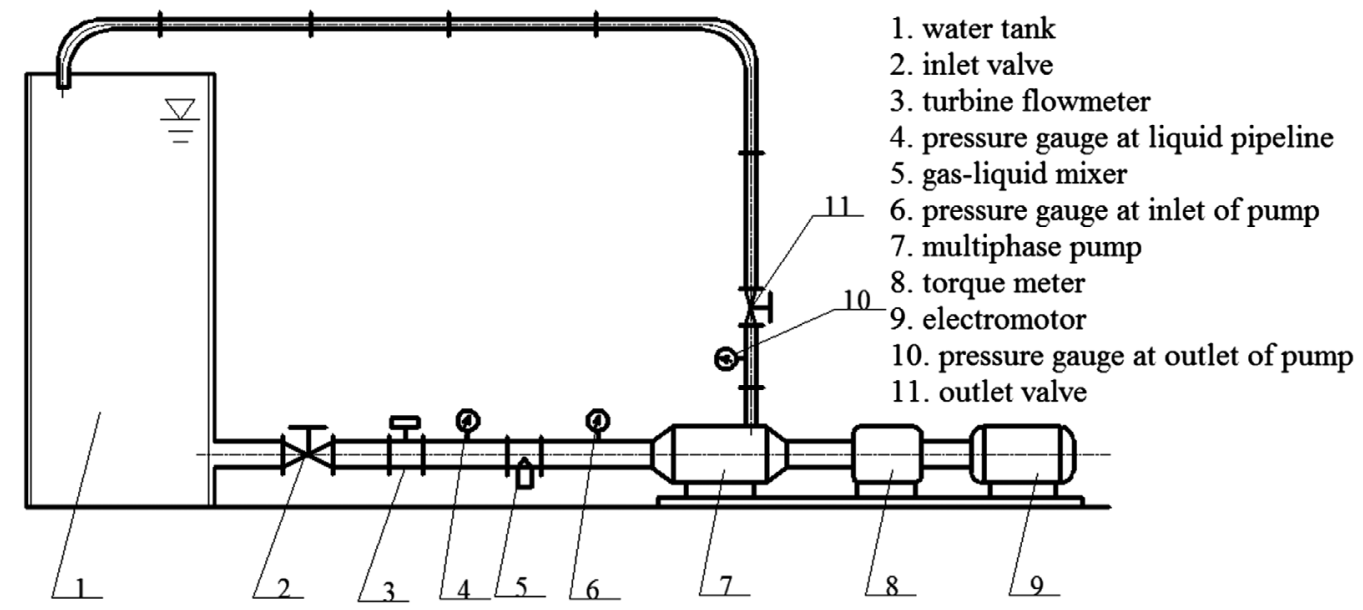

Fig. 3. Schematic diagram of the testing system.

$$
\begin{aligned}
& \phi=c_{\mathrm{m} 2} / u_{2} \\
& \psi=g H / u_{2}^{2}
\end{aligned}
$$

where $Q_{\mathrm{g}}$ and $Q_{\mathrm{l}}$ represent the volume discharge of gas and liquid, respectively, at the inlet, and $c_{\mathrm{m} 2}$ and $u_{2}$ represent the meridional velocity and the circumferential velocity at impeller outlet, respectively. The dischargehead performance curves from the simulation showed close agreement with the experiment. The errors of head at design conditions of $I G V F=0$ and $I G V F=15 \%$ are $1.39 \%$ and $4.9 \%$, respectively. Therefore, the simulation model used in the present study is reliable.

\subsection{Influence of IGVF on gas-liquid flow characteristics}

Through the CFD_Post, the area average of GVF along the flow direction was obtained at different IGVF $(5 \%, 15 \%$, and $25 \%)$ and a total discharge coefficient $\varphi$ of 0.043 for the air-water medium, as shown in Figure 5 . At these three $I G V F$ conditions, a uniform gas distribution appeared at the inlet pipe, while the gas in the impeller mainly gathered at the hub. This accumulation was attributed to the rotating effect of the impeller. The liquid phase, with a greater density, experienced larger centrifugal force, and as a result, moved towards the impeller shroud, whereas the gas gathered near the impeller hub. 


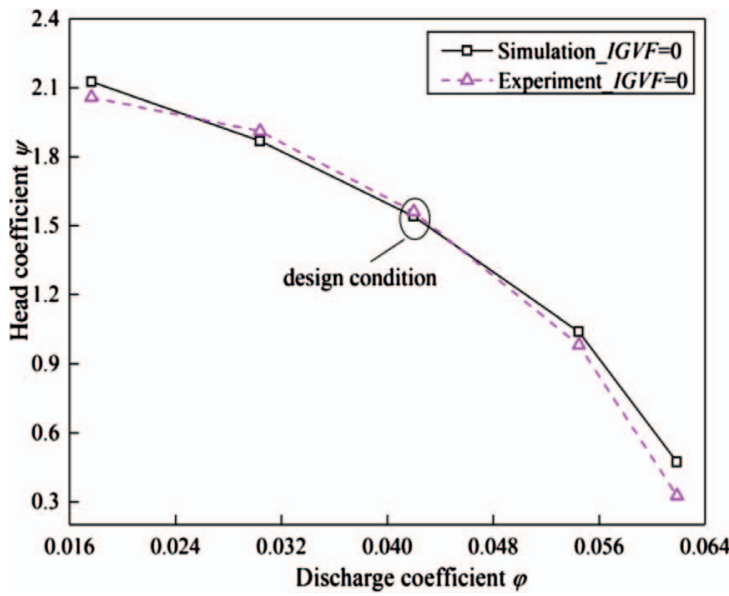

a) $I G V F=0 \%$

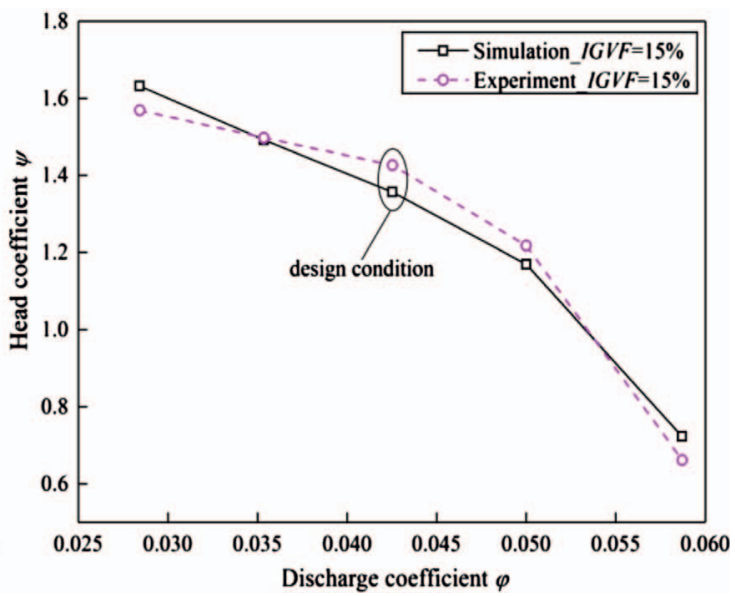

b) $I G V F=15 \%$

Fig. 4. Discharge-head curves for simulation and experiment.

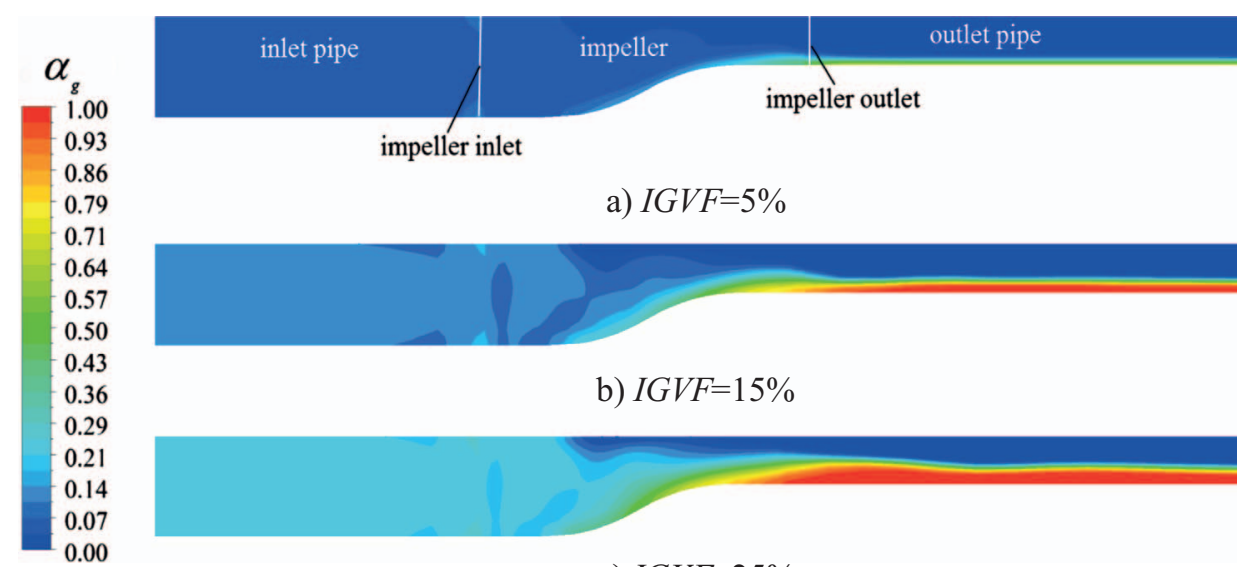

c) $I G V F=25 \%$

Fig. 5. Distribution of GVF at conditions of $I G V F=5 \%, 15 \%$ and $25 \%(\varphi=0.043)$.

When the $I G V F$ value was raised, the degree of gas aggregation in the impeller hub and the gas inhomogeneity in the entire impeller increased, resulting in the reduction of pressure boosting of the pump, as shown in Figure 6. Furthermore, it can be seen from Figure 5 that a stratified structure appeared in the outlet pipe, that is, the gas and the liquid accumulated at the hub and the shroud, respectively. This is caused by the movement of gas. Because of the inertia, the gas accumulating near the impeller hub will move along the streamwise direction, thus the gas-liquid stratified structure came into being. Moreover, the stratified structure became more obvious with the increase in $I G V F$.

The area average of interphase forces, extracted from the inlet to the outlet of computational domain, are shown in Figure 7. Overall, the drag force, as well as the added mass and lift forces, firstly increased and then decreased along the flow direction, while the turbulent dispersion force increased gradually. The comparing of the magnitude of these four interphase forces showed that the drag force was the largest, followed by the added mass and lift forces, and then the turbulent dispersion force, where the value of the turbulent dispersion force was negligible relative to the other forces.

From Figure 7, it can be also observed that the interphase forces in the impeller passage became large with the increased IGVF. This is because the GVF is one of the factors that affect the interphase forces of drag, lift, and added mass according to Equations (5), (8) and (10), and has a positive correlation with them. While Equation (9) shows that the turbulent dispersion force has a positive correlation with the varying gradient of phase void fraction, and combined with Figure 5, the varying gradient of phase void fraction increased with the increased $I G V F$. 


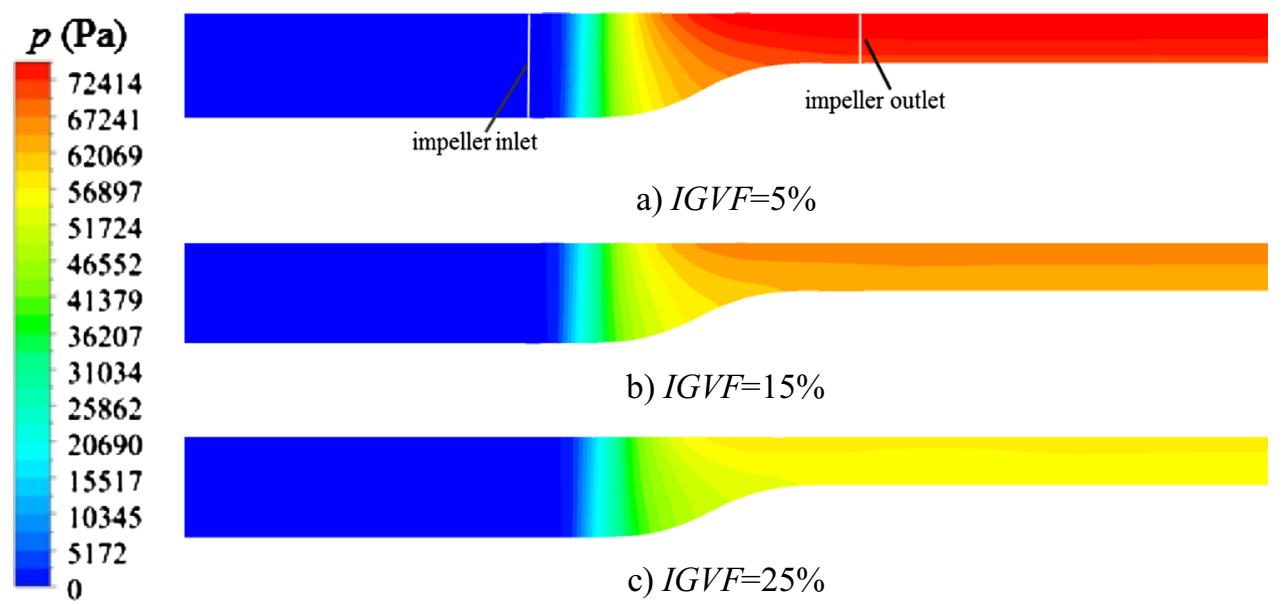

Fig. 6. Distribution of pressure at conditions of $I G V F=5 \%, 15 \%$ and $25 \%(\varphi=0.043)$.

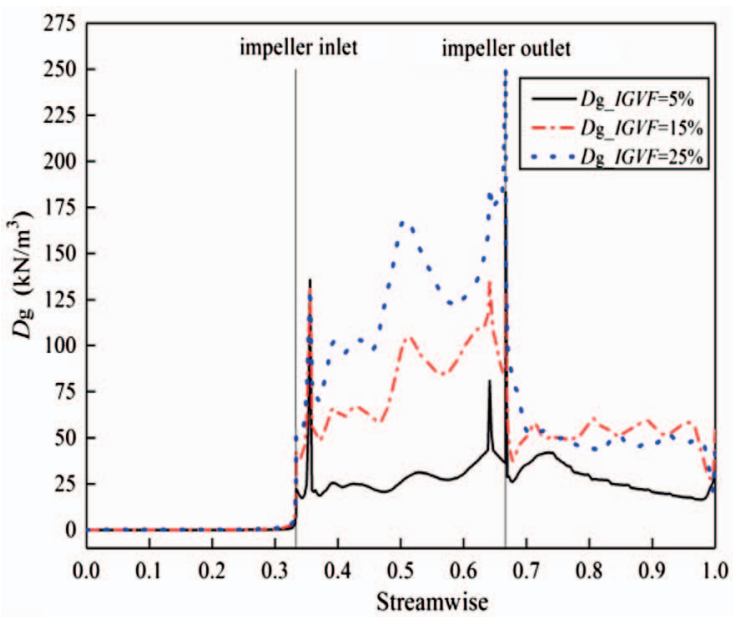

a) Drag force

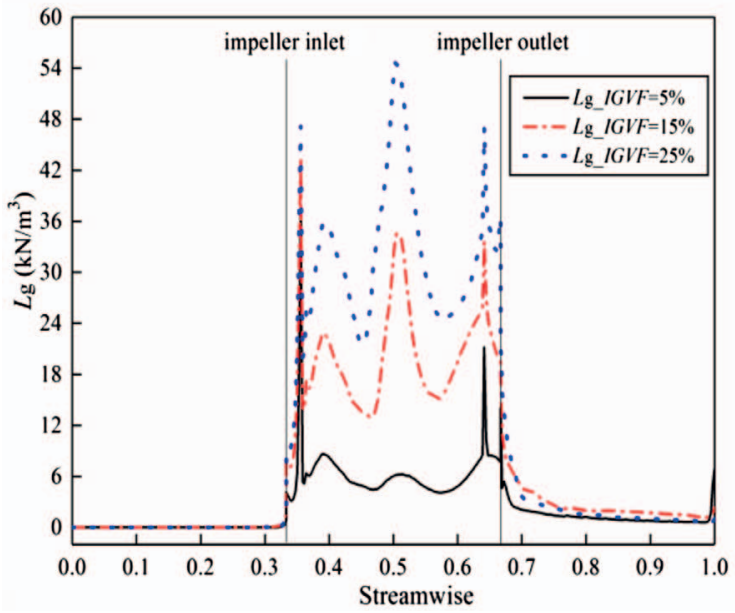

c) Lift force

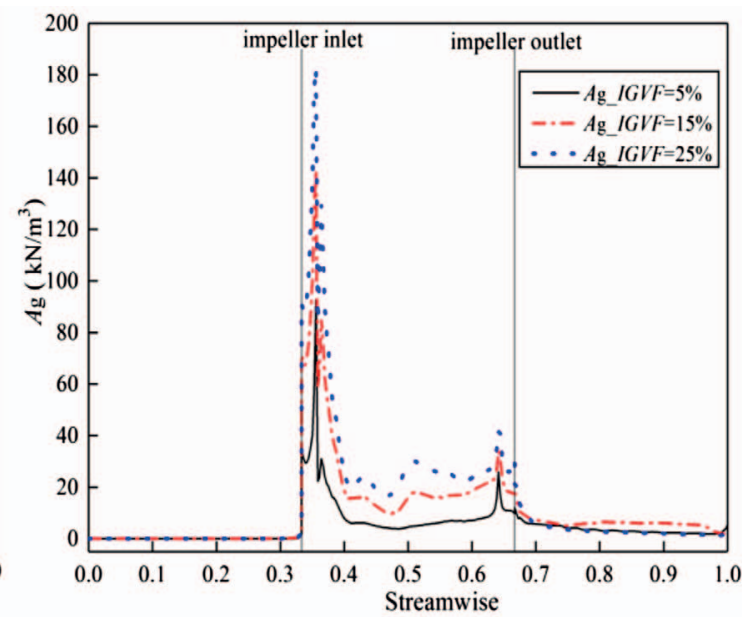

b) Added mass force

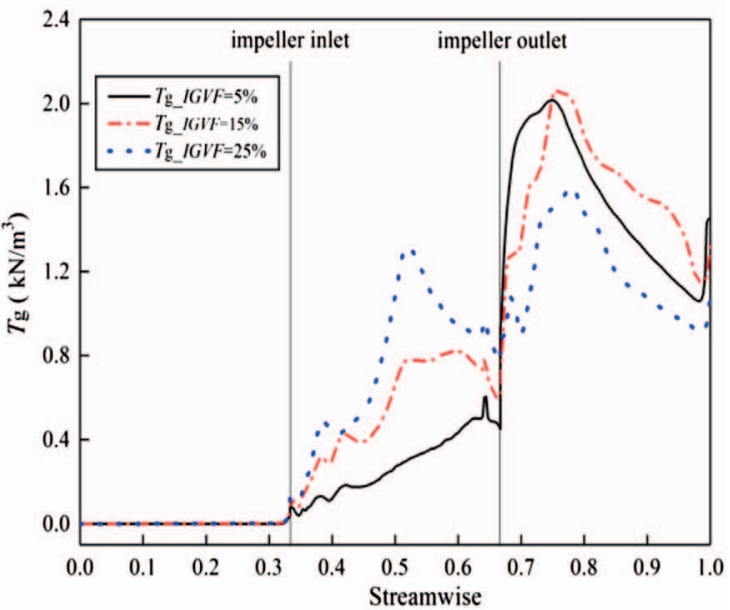

d) Turbulent dispersion force

Fig. 7. Variation of interphase forces at conditions of $I G V F=5 \%, 15 \%$ and $25 \%(\varphi=0.043)$. 


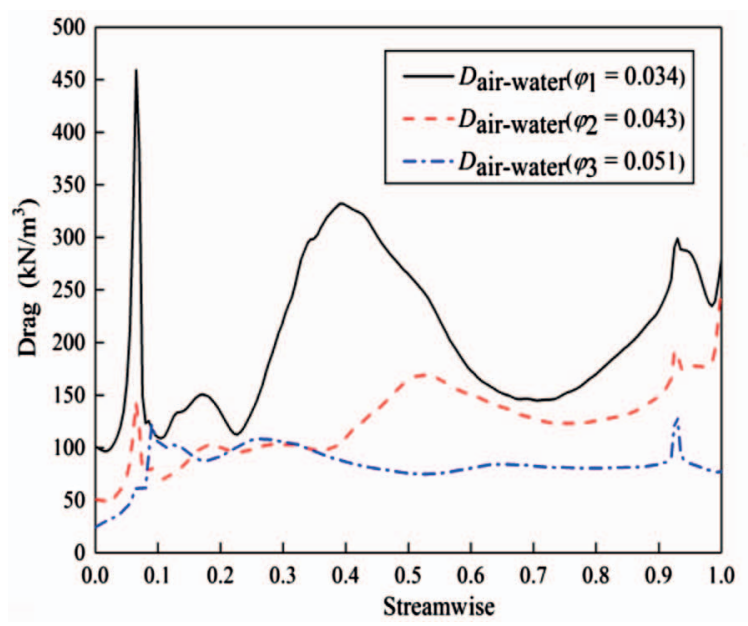

a) Drag force

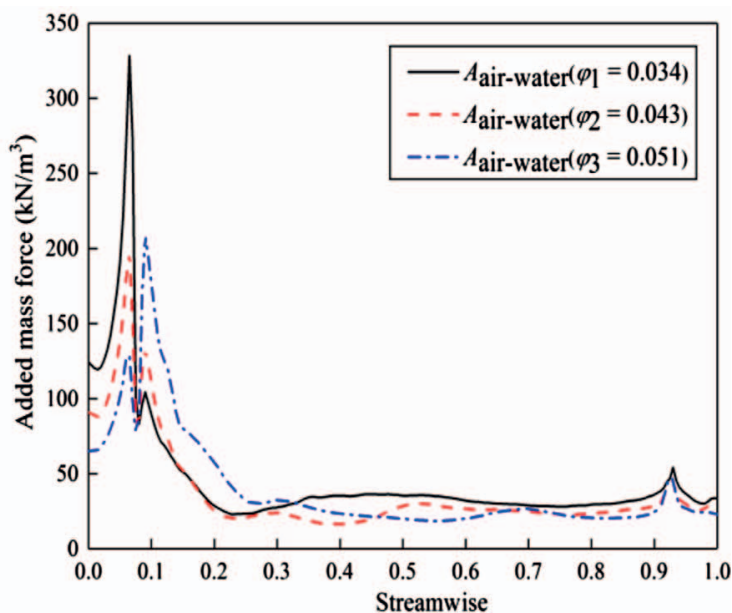

b) Added mass force

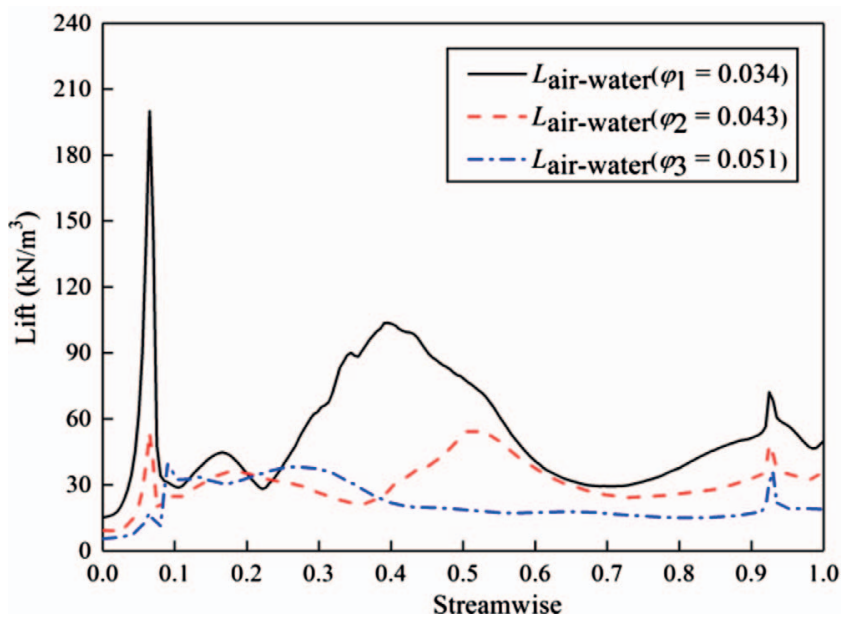

c) Lift force

Fig. 8. Variation of interphase forces in the impeller at different discharge coefficients (IGVF $=25 \%$ ).

\subsection{Influence of discharge coefficient on gas-liquid flow characteristics}

For the air-water medium at $I G V F$ of $25 \%$, the variation trend of the interphase forces along the flow direction in impeller at different total discharge coefficients $(\varphi=0.034,0.043,0.051)$ are displayed in Figure 8. The drag force, as well as the added mass and lift forces, near the impeller inlet increased significantly, which was closely related to the incidence angle that depends on the discharge coefficient. Because of the inconsistency between the incidence angle and the blade angle, the flow near the impeller inlet was more disordered, resulting in the enlarged local velocity difference between the two phases (Fig. 10).

Figure 8 also shows that the drag and lift forces generally increased with the decrease in discharge coefficient. This is because, when the discharge coefficient decreased, the GVF near the impeller hub, and the velocity difference between gas and liquid near the impeller inlet, increased

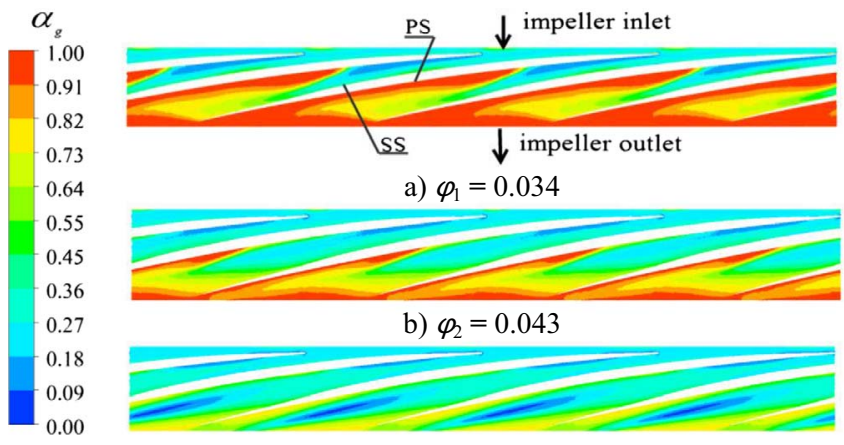

c) $\varphi_{3}=0.051$

Fig. 9. Variation of GVF near the impeller hub at different discharge coefficients $($ span $=0.1, I G V F=25 \%$ ).

obviously (Figs. 9 and 10), then combined with the corresponding equations, it can be concluded that these two interphase forces would increase. The interphase forces 


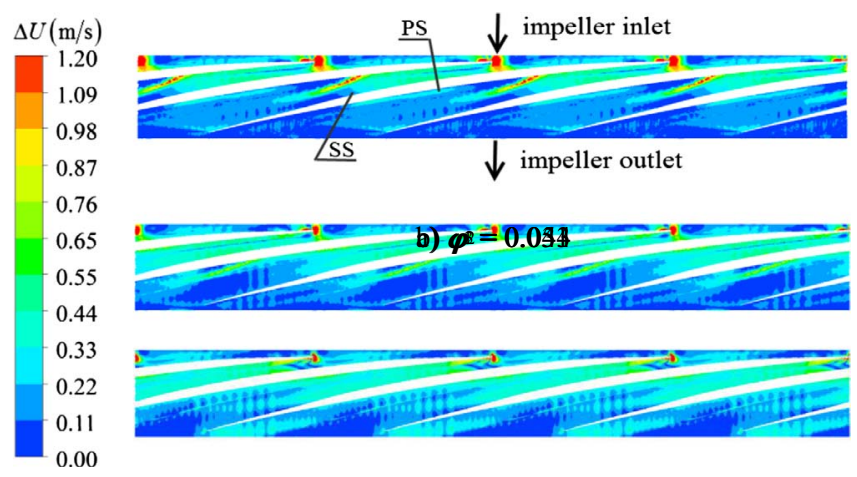

Fig. 10. Variation of velocity difference between gas and liquid near the impeller hub at different discharge coefficients $($ span $=0.1, I G V F=25 \%)$.

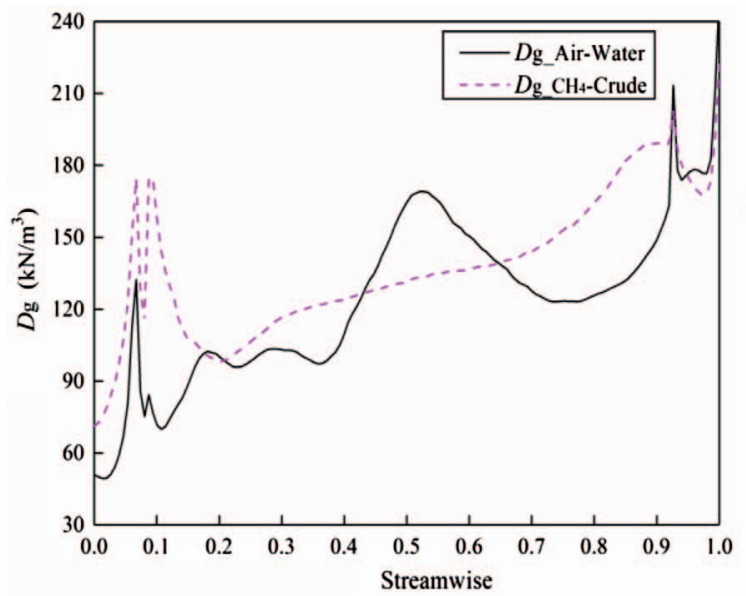

a) Drag force

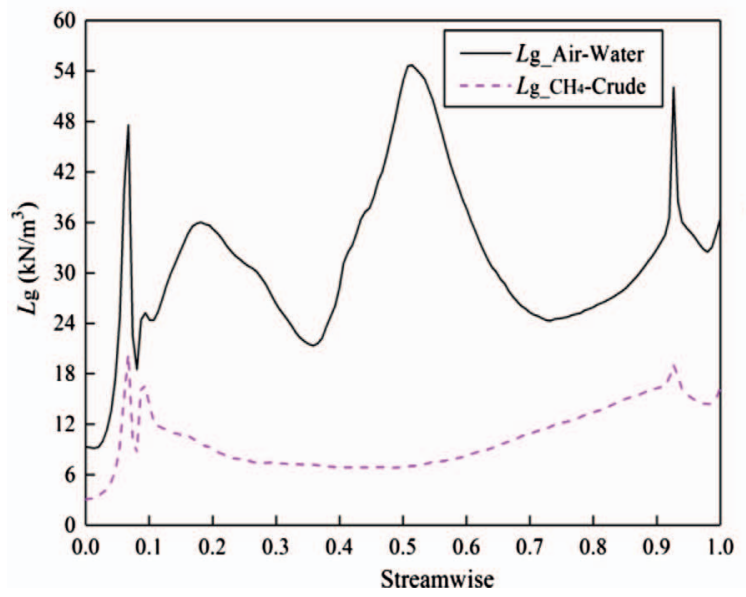

c) Lift force

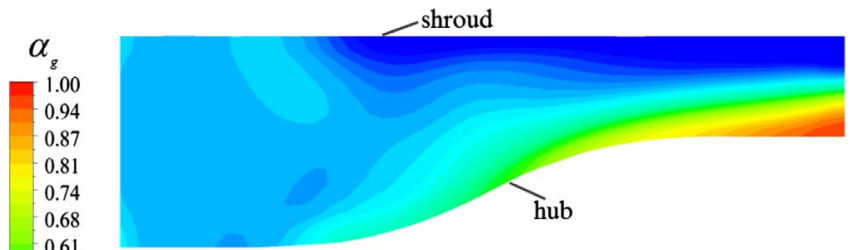

a) Air-water

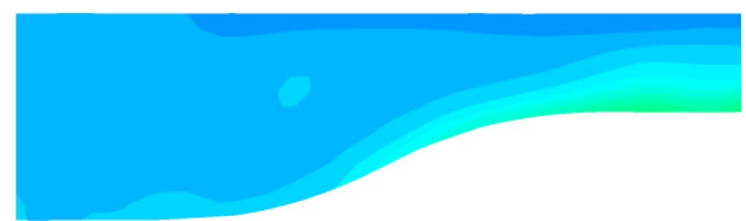

b) Air-Crude

Fig. 11. Variation of GVF at impeller meridional surface $(\varphi=0.043, I G V F=25 \%)$.

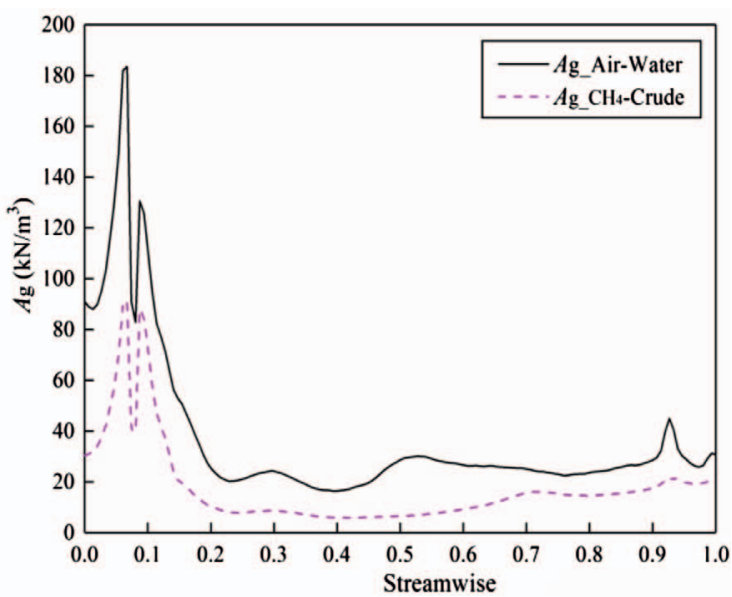

b) Added mass force

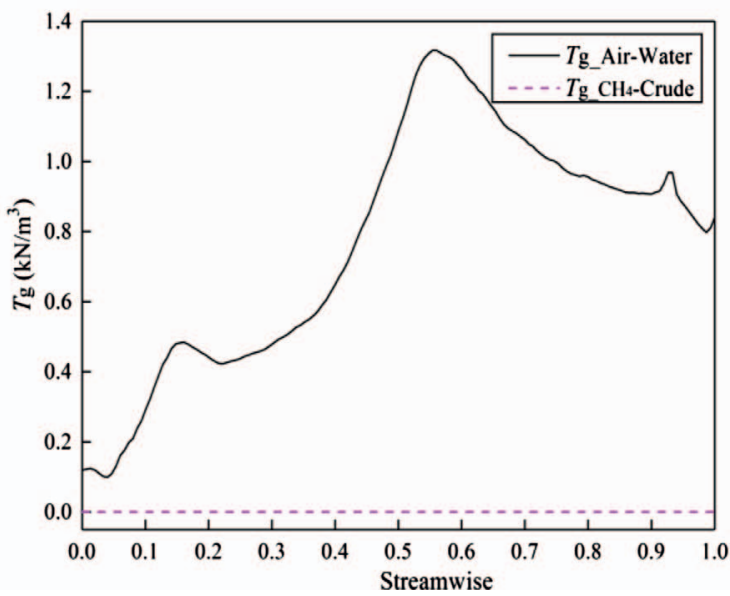

d) Turbulent dispersion force

Fig. 12. Variation of interphase forces in the impeller for different medium combinations $(\varphi=0.043, I G V F=25 \%)$.

increased dramatically when the discharge coefficient decreased to 0.034 . This was due to the large deviation between the incidence angle and the blade angle at $\varphi=0.034$. The flow separation occurred near the Suction Surface (SS), and the gas-liquid velocity difference increased. This caused the water motion from the Pressure 
Surface (PS) to the suction surface resulting in high accumulation of gas near the suction surface (Fig. 9).

\subsection{Influence of viscosity on gas-liquid flow characteristics}

To explore the influence of transport medium viscosity on the two-phase flow characteristics in multiphase pumps, the area average of GVF at impeller meridional surface at $\varphi=0.043$, and $I G V F=25 \%$, for air-water and air-crude mediums are shown in Figure 11.

For these two medium combinations, the regularities of gas distribution were similar, namely it gathered at the impeller hub and the closer to the impeller outlet, the higher degree of gas aggregation. Meanwhile, the gas void fraction near the impeller hub was lower for the air-crude in comparison with the air-water medium. This is because the viscosity of crude is much greater than that of water, while small density difference exists between these two mediums, thus resulting in the smaller Reynolds number for crude at the same value of discharge coefficient. The viscosity force of the crude had a greater effect on the field, and the flow velocity disturbed by the impeller was attenuated because of the greater viscosity, resulting in the lower gas void fraction near the impeller hub for the air-crude medium.

Figure 12 shows the variation trend of interphase forces in the impeller at conditions of $\varphi=0.043, I G V F=25 \%$. For the air-crude medium, the drag force was the largest interphase force, followed by the added mass and lift forces, and then the turbulent dispersion force was the least, which can be neglected because of the smaller magnitude relative to the other forces.

The comparison of the interphase forces at these two medium combinations showed that for the air-crude combination, the variation trend of the interphase forces was relatively smooth along the flow direction. This is due to the larger viscosity of crude than that of water for the air-crude medium. The flow velocity disturbed by the impeller was attenuated because of the greater viscosity, thus, reducing the disorder of flow.

\section{Conclusion}

The purpose of this study is to explore the effects of different inlet parameters (inlet gas void fraction, discharge, medium viscosity) on the characteristics of flow and phase interaction in a gas-liquid multiphase pump, which is contribute to the optimization design for such pumps. Through the numerical calculation, several conclusions can be obtained below:

When the medium is the combination of air-water, a uniform gas distribution appeared at the inlet pipe, and a stratified structure was formed in the outlet pipe, while the gas in the impeller gathered at the hub because of the rotation effect of impeller. The interphase forces along the flow direction firstly increased and then decreased except the turbulent dispersion force, which increased gradually. Meanwhile, all the four interphase forces in impeller were increased with the increased $I G V F$.
When the medium is the combination of air-water, because of the inconsistency between the incidence angle and the blade angle, the drag force, as well as the added mass and lift forces, near the impeller inlet increased significantly. As the discharge coefficient decreased, the gas void fraction near the impeller hub, and the gas-liquid velocity difference near the impeller inlet increased obviously, resulting in the increased drag and lift forces.

For the two medium combinations, the regularities of gas distribution were similar, namely it gathered at the impeller hub and the closer to the impeller outlet, the higher degree for gas aggregation. Due to the larger viscosity of crude, the flow velocity disturbed by the impeller was attenuated, which resulted in the lower gas void fraction near the impeller hub for air-crude medium.

For the two medium combinations, the drag force was the largest interphase force, followed by the added mass and lift forces, and then the turbulent dispersion force was the least and thereby can be neglected. Due to the larger viscosity of crude than that of water, the variation trend of the interphase forces in impeller was relatively smooth for the air-crude medium.

Acknowledgments. This study was supported by the National Natural Science Foundation of China (grant no. 51579006), and Basic Research Foundation of Beijing Institute of Technology (grant No. 20150342012).

\section{References}

1 Liu X., Liu C., Yang Y. (2017) Dynamic behavior of the polished rod for the coalbed methane pumping installations, Oil Gas Sci. Technol. - Rev. IFP Energies nouvelles $\mathbf{7 2}, 16$.

2 Falcimaigne J., Brac J., Charron Y., Pagnier P., Vilagines R. (2002) Multiphase pumping: achievements and perspectives, Oil Gas Sci. Technol. - Rev. IFP Energies nouvelles 57, 1, 99-107.

3 Omrani A., Franchek M., Ebrahimi B., Mutlu M., Grigoriadis K. (2017) Low-dimensional modeling of a pumping unit to cope with multiphase, J. Dyn. Syst. Mea. Control. 139, 4, 1-4.

4 Pirouzpanah S., Gudigopuram S., Morrison G. (2016) Twophase flow characterization in a split vane impeller Electrical Submersible Pump, J. Petrol. Sci. Eng. 148, 82-93.

5 Minemura K., Murakami M. (1980) A theoretical study on air bubble motion in a centrifugal pump impeller, J. Fluid. Eng. - ASME 102, 446-453.

6 Minemura K., Murakami M. (1993) Three-dimensional calculation of air-water twophase flow in centrifugal pump impeller based on a bubbly flow model, J. Fluid. Eng. - ASME 115, 766-771.

7 Minemura K., Murakami M. (1974) Effects of entrained air on the performance of a centrifugal pump, Bull. Japan Soc. Mech. Eng. 112, 1286-1295.

8 Caridad J., Asuaje M., Kenyery F., Tremante A., Aguillon O. (2008) Characterization of a centrifugal pump impeller under two-phase flow conditions, J. Petrol. Sci. Eng. 63, 18-22.

9 Zhang J.S., Tan L. (2018) Energy performance and pressure fluctuation of a multiphase pump with different gas volume fractions, Energies 11, 1-14. 
10 Tremante A., Moreno N., Rey R. (2002) Numerical turbulent simulation of the two-phase flow (liquid/gas) through a cascade of an axial pump, J. Fluid. Eng. - ASME 124, 371-376.

11 Ishii M., Zuber N. (1979) Drag coefficient and relative velocity in bubbly, droplet or particulate flows, AIChE J. 25, $843-855$.

12 Ion I., Mostafa F., Faïcal L. (2003) Hydrodynamic model for horizontal two-phase flow through porous media, Can. J. Chem. Eng. 81, 957-962.

13 Laurien E., Niemann J. (2004) Determination of the virtual mass coefficient for dense bubbly flows by direct numerical simulation, 5th International Conference on Multiphase Flow, Yokohama, Japan, June.

14 Yu Z.Y., Zhu B.S., Cao S.L. (2015) Interphase force analysis for air-water bubbly flow in a multiphase rotodynamic pump, Eng. Comput. 32, 2166-2180.

15 Zhang W.W., Yu Z.Y., Zahid M.N., Li Y.J. (2018) Study of the gas distribution in a multiphase rotodynamic pump based on interphase force analysis, Energies 11, 1-16.

16 Lee D., Best F.R., McGraw N. (1987) Microgravity twophase flow regime modeling, Proceedings of the Nuclear Society Winter Meeting, Los Angeles, CA, USA, November.

17 Benhmidene A., Chaouachi B., Bourouis M., Gabsi S. (2011) Numerical prediction of flow patterns in bubble pumps, J. Fluid. Eng. - ASME 133, 1-8.

18 Situ R., Hibiki T., Brown R.J. (2011) Flow regime transition criteria for two-phase flow at reduced gravity conditions, Int. J. Multiph. Flow. 37, 1165-1177.

19 Zhang W.W., Yu Z.Y., Zhu B.S. (2017) Numerical study of pressure fluctuation in a gas-liquid two-phase mixed-flow pump, Energies 10, 1-14.

20 Tan L., Zhu B.S., Cao S.L., Wang Y.C., Wang B.B. (2013) Numerical simulation of unsteady cavitation flow in a centrifugal pump at off-design conditions, Proc. Inst. Mech. Eng. C: J. Mech. Eng. Sci. 228, 1994-2006.
21 Tan L., Zhu B.S., Cao S.L., Wang Y.M. (2013) Cavitation flow simulation for a centrifugal pump at a low flow rate, Chin. Sci. Bull. 58, 949-952.

22 Such J.W., Kim J.W., Choi Y.S., Kim J.H., Joo W.G., Lee K.Y. (2017) Multi-objective optimization of the hydrodynamic performance of the second stage of a multi-phase pump, Energies 10, 1-21.

23 Zhang W.W., Yu Z.Y., Zahid M.N., Li Y.J. (2018) Study of the gas distribution in a multiphase rotodynamic pump based on interphase force analysis, Energies 11, 5, $1-16$.

24 Liu D.Y. (1993) Fluid Dynamics of two-phase systems, Higher Education Press, Beijing, China, pp. 26-31.

25 Yu Z.Y., Zhu B.S., Cao S.L., Liu Y. (2015) Effect of virtual mass force on the mixed transport process in a multiphase rotodynamic pump, Adv. Mech. Eng. 6, 1-7.

26 Johnson R.W. (1998) The handbook of fluid dynamics, Boca Raton, FL, USA, pp. 21-22.

27 Schiller L., Naumann A. (1993) Fundamental calculations in gravitational processing, Z. Ver. Dtsch. Ing. 77, 318-320.

28 Zhang J.Y., Li Y.J., Cai S.J., Zhu H.W., Zhang Y.X. (2016) Investigation of gas-liquid two-phase flow in a three-stage rotodynamic multiphase pump via numerical simulation and visualization experiment, Adv. Mech. Eng. 8, 1-13.

29 Tabib M.V., Schwarz P. (2011) Quantifying sub-grid scale (SGS) turbulent dispersion force and its effect using oneequation SGS large eddy simulation (LES) model in a gas-liquid and a liquid-liquid system, Chem. Eng. Sci. 66, 3071-3086.

30 Mohajerani M., Mehrvar M., Eincmozaffari F. (2012) CFD analysis of two-phase turbulent flow in internal airlift reactors, Can. J. Chem. Eng. 60, 1611-1630.

31 Pourtousi M., Sahu J.N., Ganesan P. (2014) Effect of interfacial forces and turbulence models on predicting flow pattern inside the bubble column, Chem. Eng. Process: Process Intensification 75, 38-47. 